\title{
Plagiarism and Plunder: Fabrication and Falsification
}

Jose Florencio F. Lapeña, Jr. MA, MD ${ }^{1,2}$

'Department of Otorhinolaryngology College of Medicine - Philippine General Hospital University of the Philippines Manila

${ }^{2}$ Department of Otorhinolaryngology Head and Neck Surgery

East Avenue Medical Center

Diliman, Quezon City, Philippines

Correspondence: Jose Florencio F. Lapeña, Jr. MA, MD

Department of Otorhinolaryngology

Ward 10, Philippine General Hospital

University of the Philippines Manila

Taft Ave., Ermita, Manila 1000

Philippines

Phone (632) 5264360

Fax (632) 5679508

Email lapenajf@upm.edu.ph

Reprints will not be available from the author.

The author declared that this represents original material that is not being considered for publication or has not been published or accepted for publication elsewhere, in full or in part, in print or electronic media; that the manuscript has been read and approved by the author, that the requirements for authorship have been met by the author, and that the author believes that the manuscript represents honest work.

Disclosures:

Professor Lapeña is Secretary-General of the Asia Pacific Association of Medical Journal Editors (APAME), and a member of the World Association of Medical Editors (WAME), which have policy positions against plagiarism that he echoes. He has no other relevant conflicts of interest to declare.

\author{
"You, who are on the road \\ Must have a code that you can live by \\ And so, become yourself \\ Because the past is just a good bye" 1
}

The recent dismissal of charges of plagiarism made against no less than a Justice of the Supreme Court of the Republic of the Philippines ${ }^{2}$ and subsequent retaliatory threats against protesting faculty of the College of Law of the University of the Philippines ${ }^{3}$ are matters of grave concern in a country where even the capital crime of plunder can be so blatantly disregarded. Not surprisingly, these misdemeanors share a similar etymology.

Plagiarism comes from the "Latin plagiarius 'kidnapper, seducer, plunderer,' used in the sense of 'literary thief' by Martial, from plagium 'kidnapping,' from plaga 'snare, net."' ${ }^{\prime 4}$ According to the World Association of Medical Editors, "plagiarism is the use of others' published and unpublished ideas or words (or other intellectual property) without attribution or permission, and presenting them as new and original rather than derived from an existing source. ${ }^{15}$ Just as ignorance of the law is not an excuse to violate it, the misconduct of plagiarism is not contingent on whether it was committed intentionally or unintentionally. Technical Plagiarism "occurs when one inadvertently fails to properly cite, credit, and/or integrate a source, be it text, computer code, graphic, audio, or video information into one's work ... (and) can range in severity from an errant footnote, to incomplete citation information to "forgetting" to cite altogether."

Five general types of plagiarism have been identified by Barnbaum:" "cut and paste," "word-switch," "style," "metaphor," and "idea." The first two are easy to understand, the first referring to literally lifting and applying words, phrases, sentences or paragraphs while the second involves substituting words or paraphrasing without attribution. But even following the flow of thought or reasoning style of another, substituting your own words sentence after sentence or paragraph after paragraph is "style plagiarism" and the same holds true when the metaphors or ideas of another are used without proper acknowledgement. ${ }^{7}$ The bottom line is that plagiarism gives the false impression that the words, ideas, composition or creation are those of the plagiarizer and not someone else's, or misleads the recipient about the nature of the plagiarized material. ${ }^{5}$ 
There is even "self-plagiarism," which "refers to the practice of an author using portions of their previous writings on the same topic in another of their publications, without specifically citing it formally in quotes," give the impression that the present work is new and original, when in fact it is not. According to Scanlon, ${ }^{8}$ while the whole issue of self-plagiarism "raises knotty conceptual, legal, ethical, and theoretical questions ... we do and should give writers legal and ethical latitude for limited self-copying, although certainly not for egregious duplication."

Barring situational concessions for limited self- and technical plagiarism in exceptional contexts, plagiarism generally involves fabrication and falsification, which in science (as in law) are misconducts of the highest degree, regardless of the presence or absence of "malicious intent."

The Code of Conduct and Best Practice Guidelines for Journal Editors of The Committee on Publication Ethics (COPE) outlines the duties of editors in pursuing such misconduct: ${ }^{9}$

\section{PURSUING MISCONDUCT}

Editors have a duty to act if they suspect misconduct. This duty extends to both published and unpublished papers.

Editors should not simply reject papers that raise concerns about possible misconduct. They are ethically obliged to pursue alleged cases.

Editors should first seek a response from those accused. If they are not satisfied with the response, they should ask the relevant employers or some appropriate body (perhaps a regulatory body) to investigate.

Editors should follow the COPE flowcharts where applicable (link to flowcharts).

Editors should make all reasonable efforts to ensure that a proper investigation is conducted; if this does not happen,

Editors should make all reasonable attempts to persist in obtaining a resolution to the problem. This is an onerous but important duty.
If this "onerous but important duty" applies to scientific misconduct, how much more to an institution whose very foundations are based on ethics and morality and whose raison d'etre is their upholding? Where resides this institution's moral authority, if it cannot set the example it ought to?

It is not right to take what is not yours without permission; that is thievery at best. It is even worse to shamelessly appropriate for yourself, that which belongs to others; that is looting and piracy. But the large-scale wanton stripping of intellectual (and other) properties and subsequent justification with legalese that violate the very roots of academic (and other) freedoms for present and future generations are tantamount to no less than pillage and plunder. 